\title{
Addressing health workers' exposure to violence at Lebanese emergency departments: What do the stakeholders think?
}

\author{
Mohamad Alameddine, Nasser Yassin \\ Health Management and Policy Department, Faculty of Health Sciences, American University of Beirut, Lebanon \\ Correspondence: Nasser Yassin. Address: Health Management and Policy Department, Faculty of Health Sciences, \\ American University of Beirut, Lebanon. E-mail: nasser.yassin@aub.edu.lb
}

Received: December 23, 2012

Accepted: January 30, 2012

Online Published: April 28, 2013

DOI : $10.5430 /$ jha.v2n4p31

URL: http://dx.doi.org/10.5430/jha.v2n4p31

\begin{abstract}
Healthcare settings are notorious for exposing their employees to high levels of verbal and physical violence. A recent study on occupational violence at Lebanese Emergency Departments (EDs) revealed that $70 \%$ of surveyed ED workers were exposed to at least one incidence of violence over the last twelve months. Acting on the findings of this study a multi-stakeholder policy forum was held with key ED stakeholders to discuss possible policy and practice changes to reduce health workers' exposure to occupational violence. Stakeholder deliberations revealed that the root causes of violence in EDs could be classified under three main categories relating to the administration of EDs including the presence of antiviolence policies, the management of human resources, and balancing patient expectations. Stakeholders built a consensus on a number of remedial actions at the societal, health care facility and policy levels. Engaging with various stakeholders in an open forum was a unique initiative that contributed to building a consensus among key stakeholders on a road map to help protect health workers in EDs and beyond.
\end{abstract}

\section{Key words}

Occupational violence, Human resources, Emergency departments, Policy

\section{I ntroduction}

Healthcare settings are notorious for exposing their employees to high levels of violence; with violence related injury rates reported to be four times higher than any other employment setting ${ }^{[1]}$. Violence encompasses verbal abuse, physical assault as well as sexual harassment; with the former being the most commonly reported type of violence ${ }^{[2-7]}$. There is a consensus in literature that ED workers have a disproportionally higher exposure to violence compared to other hospital departments and that nurses are the most vulnerable to violent incidents ${ }^{[2-4]}$.

Exposure to violence precipitates serious physical, psychological and professional consequences on healthcare workers, including: impaired job performance, moderate to severe and long-term psychological effects, burnout and turnover ${ }^{[6,8,9]}$. Despite its serious consequences, most healthcare workers tend to underreport their exposure to violent incidents ${ }^{[4,6,10,11] \text {; }}$ thus it becomes important to probe them systematically in order to unearth their true rate of exposure to violence. 
Within the Lebanese context, a recent study entitled "Occupational violence at Lebanese emergency departments: prevalence, characteristics and associated factors” which examined health workers' exposure to violence at Lebanese emergency departments (EDs) revealed that 70\% of surveyed ED workers were exposed to violence at least once over the last twelve months. The study further unearthed three main findings; first, nurses were disproportionally exposed to physical violence with more than a third of surveyed nurses subjected to at least one incidence of physical violence over the last 12 months. Second, public hospitals displayed a significantly higher level of exposure to occupational violence compared to academic medical centers and private hospitals. Finally, the study revealed that many of the root causes of violence are amendable to interventions, yet would require a multi-disciplinary approach in the design of these interventions $^{[12]}$.

\section{Methods}

Prompted by the results of the aforementioned study, the authors of this paper organized and facilitated a multi-stakeholder Policy Forum on Violence and Aggression in Emergency Departments (ED) in Lebanon in April 2011. The aim of the forum was to engage with policymakers, decision makers and other concerned actors on possible changes to reduce the exposure of healthcare workers to violence. More specifically, the forum was designed to address the underlying causes of violence in EDs and engage in possible solutions at three levels: societal, health care facility and public policy.

Participating stakeholders were selected based on their constituency representation. State actors included the Ministry of Public Health and the Internal Security Forces (Police Department). The latter were represented by a senior staff member in the police medical corps. Non-state actors included international Non Governmental Organizations (NGOs), national NGOs, representatives of major media channels, and representatives of the main stewardship bodies including the Order of Physicians, Syndicate of Nurses and Syndicate of Private Hospitals. Other stakeholders who participated in the discussion forum included leaders and administrators from major public and private hospitals. The total number of participants in the discussion was 25 stakeholders.

After presenting the main findings of the occupational violence at Lebanese emergency department's study (12), discussions were held in three subgroups with each deliberating on same policy issues. In order to ensure a comprehensive perspective on the issue, participants were divided into three sub-groups based on sectoral representation. The first consisted of healthcare facilities leaders and administrators, the second comprised stewardship bodies and the third included representatives of governmental and non-governmental bodies.

Group discussions were structured to allow for optimal flow of ideas among the participants around three main issues: 1the causes of workers' exposure to occupational violence at Lebanese EDs; 2- the particular susceptibility of nurses and public hospital employees; and 3- policy and practice recommendations to help protect ED workers. Each group identified the root causes of ED violence and came up with a series of recommendations that could pave the way to creating a safer work environment for ED staff and consequently for other healthcare workers. Recommendations looked at the role of each actor, state and non-state, and included mechanisms for implementation. All attendants discussed and approved the recommendations included in this report.

The discussions within the groups were recorded and later transcribed. To understand what are the factors contributing to violence in the ED, analysis was undertaken based on three main themes/questions: what is the role of hospital administration in contributing to or curtailing violence? How does human resources management play a role in this type of violence? How communication/miscommunication with patients and their families contribute to aggravating or curtailing violence? Consequently, recommendations were analyzed based on three levels: at the health care facility, at policy and at societal levels. 


\section{Stakeholders' identification of roots of violence in ED}

A general discussion between stakeholders revolved around issues of violence towards health care workers in general and nurses in particular. Stakeholders identified a myriad of factors contributing to violence and were related to three main areas: hospital administrations, human resources management, and patient expectations/ communication problems (Table 1).

Table 1. Summary of Policy Forum Deliberations and Recommendations

\begin{tabular}{|c|c|c|}
\hline Issues at stake & Roots of Violence & Recommended corrective measures \\
\hline Hospital Administration & $\begin{array}{l}\text {-Giving preference to private patients } \\
\text {-Working conditions of ED staff } \\
\text {-Lack of proper communication between ED staff and } \\
\text { paramedics } \\
\text {-ED staff need training on communicating with distressed } \\
\text { patients \& families } \\
\text {-Lack of ant-violence policies at hospitals }\end{array}$ & $\begin{array}{l}\text {-Encourage ED staff to report any act of } \\
\text { violence } \\
\text {-Establish stronger communication } \\
\text { channels between ED workers } \\
\text {-Train ED workers on how to deal with } \\
\text { violence }\end{array}$ \\
\hline $\begin{array}{l}\text { Human Resources } \\
\text { Management }\end{array}$ & $\begin{array}{l}\text {-Poor allocation of staff at EDs } \\
\text {-High attrition rates among experienced nurses } \\
\text {-Lack of motivation of ED staff due to limited incentives }\end{array}$ & $\begin{array}{l}\text {-Institute appropriate human resources } \\
\text { practices at healthcare facilities } \\
\text {-Provide ED workers with incentives }\end{array}$ \\
\hline Patients Expectations & $\begin{array}{l}\text {-"Culturally embedded" concept of being rich and connected } \\
\text { raises expectation of patients and their families }\end{array}$ & $\begin{array}{l}\text {-Raise awareness among the general public } \\
\text { and through media on the negative } \\
\text { consequences of resorting to violence at } \\
\text { healthcare facilities. } \\
\text {-Develop a declaration form of incidents of } \\
\text { violence in ED } \\
\text {-Establish a "National Commission" to } \\
\text { oversee all the reports on acts of violence } \\
\text { within the healthcare system }\end{array}$ \\
\hline
\end{tabular}

\subsection{Hospital administration}

Participating stakeholders voiced concerns over the following three key issues related to administration of many of the hospitals in Lebanon. First, the system's likeliness to provide faster and more comprehensive services to private patients could create tension between the economically disadvantaged patients, their family members and the front-line employees; mostly nurses. Second, participants agreed that working conditions at EDs, including: long working hours, high workload, sub-optimal salaries and benefits and unfriendly working contexts might be causing workers to become aggressive and inhospitable towards patients and families, communicate poorly with patients and family members or even commit medical errors. Third, participants raised the issue of limited training courses and professional development opportunities that could empower ED staff members to communicate with patients and families in distress and take protective measures when faced with acts of violence.

\subsection{Human resources management}

Stakeholders identified four main issues related to human resources management as key contributors to violence in the workplace. They include: first, the poor allocation of human resources (e.g. understaffing and mismanagement) which has led to role-confusion and poorer capacity to handle violent patients. It also contributed to a mismatch between the total number of staff members and the workload at EDs. Second, the high attrition rates among experienced nurses could have led to the presence of some inexperienced staff in the ED who are often unfit to handle the specificities of the work-place and do not necessarily possess the required knowledge, power and experience to deal with difficult patients and difficult 
situations. Third, the lack of motivation among many ED employees with limited financial and non-financial incentives that would enhance their retention in a risky and challenging work context. Fourth, stakeholders identified the limited knowledge of ED workers' rights as a contributing factor to the problem. For example, being unaware of their rights, nurses and other healthcare providers elect not to voice their concerns.

\subsection{Patients' expectations \& issues of miscommunication}

Stakeholders attributed a significant proportion of the acts of violence in the ED to patients' unrealistic expectations; requesting prompt services by experienced specialists without any incurred costs. They further voiced the following three concerns. First, patients' expectations are difficult to address as they are mostly related to "culturally-embedded" concepts that "being rich and connected" in Lebanon allows some patients and their families to use force and violence to acquire what they want. Thus, at many instances the perpetrators of violence were patients of higher social status and those supported by political and sectarian parties. At other instances insured patients perpetrated violence as they expect apt services from ED staff, creating a tense environment. Second, patients' violent attitudes and behaviors might have been aggravated by the lack of clear anti-violence policies at the hospitals that instruct staff members on how to deescalate violent encounters while protecting their wellbeing and that of their colleagues. Third, violence could also be caused by the lack of proper communication with paramedics (e.g. Red Cross) prior to the arrival of patients to the ED. At many instances, paramedics and transportation staff do not explain the severity of the patient's case, which creates a discrepancy in expectations between patients, accompanying family members and ED staff potentially leading to violence.

\section{Stakeholders' recommendations for change}

Stakeholder recommendations to address the aforementioned issues were collated under three main levels: health care facility, policy and society (Table 1).

\subsection{At the health care facility level}

Stakeholders declared that it should be the right of ED staff to report any acts of violence against them to their administration and to their respective order or syndicate. Other stakeholders suggested a focus on undergraduate educational programs in order to plant the seed of power and knowledge as early as possible in the medical provider's professional life.

Stakeholders stressed the need for instituting appropriate human resource practices at healthcare facilities. For example, reinforcing staffing ratios in relation to the numbers of admitted cases. In addition, there was an emphasis on the importance of special training programs aiming at enhancing ED workers' knowledge and skills in identifying and dealing with violence, which should be organized in collaboration with professional bodies and academic institutions. A number of stakeholders reported that in order to motivate and preserve ED workers' skills and work tolerance, a proper incentive and reward program accompanied with work-hour restrictions should be implemented.

Stakeholders further recommended the establishment of stronger communication channels between ED workers leading to better transparency, coordination and communication between nurses, doctors, patients, family members and the paramedic/ transportation staff. Some suggested that both patients and nurses need to be educated on their rights and duties when it comes to communicating within the ED premise.

\subsection{At the policy level}

Stakeholders recommended the legislation of mandatory reporting of any form of physical, verbal and sexual violence by healthcare facilities to orders or syndicates (specifically the order of nurses and syndicate of hospitals). It was suggested that a "declaration form" should be developed. This form will be both internal (via administration) and external (via syndicates and laws) in nature. 
Stakeholders recommended the establishment of a "National Commission" that oversees all the reports on acts of violence within the healthcare system with a constant line of communication between this commission, the syndicates/orders and the Ministry of Health. Stakeholders further recommended the establishment of policies mandating hospitals to establish a minimum set of security measures, including an internal system of cameras and security alarms to alert Lebanese security forces, "red-alert-button” and "hot-line for violence against workers”.

\subsection{At the societal level}

Stakeholders highlighted the pivotal role of media in combating violence against nurses and ED staff by offering TV spots for public awareness campaigns and providing concentrated coverage on this issue. There is an urgent need to raise awareness among the general public on the serious negative consequences of resorting to violence at health care facilities. Participants recommended, as a way to raise awareness, to commemorate a national day to denounce violence at healthcare facilities with a series of activities and concentrated media coverage to educate the society on this serious issue.

\section{Limitations}

The study has one major limitation that warrant mentioning. Although the authors aimed at optimal representations, stakeholders were conveniently selected and invited to participate in the forum. Some voices have been unintentionally omitted such as the patients' and their families'.

\section{Conclusion}

Understanding the positions of various stakeholders is paramount to produce effective programs and policies that would tackle the issue of violence in EDs. The multi-dimensional nature of ED violence necessitates a multiple stakeholder approach. The deliberations unearthed a number of priority issues that need to be addressed from various angles. More importantly, it contributed to building a consensus among key stakeholders on the need to protect health workers in EDs and beyond. Such consensus among state and non-state actors is the first step towards enacting effective policies and actions to address violence in EDs. Furthermore, the significance of prompt action on the solutions suggested is vital for the safety of employees, patients, and their families, which ultimately reflects on the proper provision of health services.

Many countries and in particular in the developing world could gain from the Lebanese experience in deliberating with state and non-state actors on the corrective measures and policy options for curtailing violence in ED. The complexity of the subject of violence and its multifaceted nature would principally require a multi-stakeholder intervention and at various levels. Furthermore, evaluating any effort taken to reduce or eliminate violence at EDs should be an integral part of any plan of action to ensure the sustainability of the interventions put in place. It is acknowledged that to operate some of the aforementioned recommendations would require investments of time and resources, and perhaps most importantly, it would need the political resolve as well as the support of all concerned stakeholders.

\section{Acknowledgements}

We would like to acknowledge the valuable assistance of Ms. Hanadi Abdel-Ahad, Ms. Sandra Arbid, Ms. Riwa Jaber, and Mr. Jad Jaber in the facilitation of the policy forum and the preparation of this report.

\section{References}

[1] Whelan T. The escalating trend of violence toward nurses. J Emerg Nurs. 2008; 34(2): 130-3. PMid:18358351 http://dx.doi.org/10.1016/j.jen.2007.05.018

[2] Taylor JL, Rew L. A systematic review of the literature: workplace violence in the emergency department. J Clin Nurs. 2010. 
[3] Winstanley S, Whittington R. Aggression towards health care staff in a UK general hospital: variation among professions and departments. J Clin Nurs. 2004; 13(1): 3-10. http://dx.doi.org/10.1111/j.1365-2702.2004.00807.x

[4] Crilly J, Chaboyer W, Creedy D. Violence towards emergency department nurses by patients. Accid Emerg Nurs. 2004; 12(2): 67-73. PMid:15041007 http://dx.doi.org/10.1016/j.aaen.2003.11.003

[5] Gacki-Smith J, Juarez AM, Boyett L, Homeyer C, Robinson L, MacLean SL. Violence against nurses working in US emergency departments. J Healthc Prot Manage. 2010; 26(1): 81-99. PMid:20229937

[6] Lau JB, Magarey J, McCutcheon H. Violence in the emergency department: A literature review. Australian Emergency Nursing Journal. 2004; 7(2): 27-37. http://dx.doi.org/10.1016/S1328-2743(05)80028-8

[7] Behnam M, Tillotson RD, Davis SM, Hobbs GR. Violence in the Emergency Department: A National Survey of Emergency Medicine Residents and Attending Physicians. J Emerg Med. 2010. PMid:20133103

[8] Fernandes CM, Bouthillette F, Raboud JM, Bullock L, Moore CF, Christenson JM, et al. Violence in the emergency department: a survey of health care workers. CMAJ. 1999; 161(10): 1245-8. PMid:10584084

[9] Pich J, Hazelton M, Sundin D, Kable A. Patient-related violence against emergency department nurses. Nurs Health Sci. 2010; 12(2): 268-74. PMid:20602701 http://dx.doi.org/10.1111/j.1442-2018.2010.00525.x

[10] Hesketh KL, Duncan SM, Estabrooks CA, Reimer MA, Giovannetti P, Hyndman K, et al. Workplace violence in Alberta and British Columbia hospitals. Health Policy. 2003; 63(3): 311-21. http://dx.doi.org/10.1016/S0168-8510(02)00142-2

[11] Gacki-Smith J, Juarez AM, Boyett L, Homeyer C, Robinson L, MacLean SL. Violence against nurses working in US emergency departments. J Healthc Prot Manage. 2010; 26(1): 81-99. PMid:20229937

[12] Alameddine M, Kazzi A, El-Jardali F, Dimassi H, Maalouf S. Occupational violence at Lebanese emergency departments: prevalence, characteristics and associated factors. J Occup Health. 2011; 53(6): 455-64. PMid:21952297

http://dx.doi.org/10.1539/joh.11-0102-OA 